\title{
Check for updates \\ Strategi Advokasi Masyarakat Sipil dalam Mendesak Pembatalan Revisi Regulasi Komisi Pemberantasan Korupsi
}

MOLNGLL OF

ISSN:2685-7766

\author{
M. Ezha Fachriza Roshady ${ }^{1 *}$, Sri Budi Eko Wardhani ${ }^{1}$ \\ ${ }^{1}$ Departemen Ilmu Politik, Universitas Indonesia, 10430, Jakarta-Indonesia
}

Info Artikel

Dikirim: Mei 31, 2021

Diterima: Juli 29, 2021

Dipublikasi: Jul 31, 2021

Kata Kunci:

Advokasi; KPK; Koalisi

Masyarakat Sipil;

Koresponden:

\section{Ezha Fachriza \\ Roshady}

Departemen Ilmu Politik,

Universitas Indonesia

Email:

ezhafr@gmail.com

Sitasi Cantuman:

Roshady, M. E. F \& Wardhani, S. B. E. (2021). Strategi Advokasi Masyarakat Sipil dalam Mendesak Pembatalan Revisi Regulasi Komisi Pemberantasan Korupsi. Journal of Political Issues. 3(1); $\quad 49-61$. https://doi.org/10.33019/jpi. v3i1.54

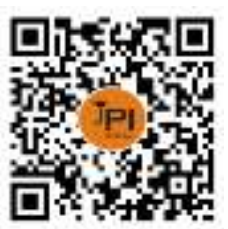

DOI:

https://doi.org/10.33019/jpi. v3i1.54

Lisensi:

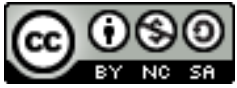

Attribution-

NonCommercial-ShareAlike

4.0 International

(CC- BY-NC-SA 4.0)

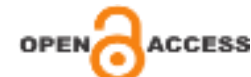

\begin{abstract}
ABSTRAK
Abstract This study aims to describe the strategy of civil society movements that are members of the anti-corruption civil society coalition. This study uses the advocacy theory of Sheldon Gen and Amy Conley Wright. The research method used is qualitative with primary data sources from interviews, and secondary data processing from various literatures relevant to this research. The anti-corruption civil society coalition controls state power by demanding that the government and the DPR be accountable to the law and the public by supporting the Corruption Eradication Commission (KPK) by not weakening the KPK institutions, and increasing public awareness of important public issues through advocacy, in this case the discourse on the Law. KPK which was revised by the DPR. In 2019 the momentum for the revision of the KPK Law was successfully carried out by the DPR together with the Government so that the advocacy carried out by the coalition failed. The anti-corruption civil society coalition adopts an advocacy strategy by strengthening a large coalition, lobbying policy makers, conducting academic studies, and labeling, media reporting, and involving and mobilizing the public in carrying out movements. Of the five advocacy strategies, in the end, it has strengths and weaknesses to carry out a social movement in influencing the policy on the revision of the KPK Law, but in the end the advocacy strategy carried out by the anti-corruption civil society coalition failed to influence policy makers and in 2019, the Law The KPK was revised on 17 September 2019.
\end{abstract}

\begin{abstract}
Abstrak Penelitian ini bertujuan untuk mendeskripsikan strategi gerakan masyarakat sipil yang tergabung dalam koalisi masyarakat sipil antikorupsi. Penelitian ini menggunakan teori advokasi dari Sheldon Gen dan Amy Conley Wright. Metode penelitian yang digunakan adalah kualitatif dengan sumber data primer dari wawancara, dan pengolahan data sekunder dari berbagai berbagai literatur yang relevan dengan penelitian ini. Koalisi masyarakat sipil antikorupsi mengontrol kekuasaan negara dengan menuntut pemerintah dan DPR bertanggung jawab kepada hukum dan publik dengan mendukung KPK (Komisi Pemberantasan Korupsi) dengan tidak melemahkan kelembagaan KPK, dan meningkatkan kesadaran publik terhadap isu-isu penting publik melalui advokasi, dalam hal ini wacana UU KPK yang direvisi oleh DPR. Pada tahun 2019 momentum revisi UU KPK berhasil dilakukan DPR bersama Pemerintah sehingga advokasi yang dilakukan oleh koalisi gagal. Koalisi masyarakat sipil antikorupsi mengadopsi strategi advokasi dengan memperkuat sebuah koalisi besar, melobi pengambil kebijakan, melakukan kajian akademik, dan pelabelan, pemberitaan media, dan melibatkan serta memobilisasi publik dalam melakukan gerakan. Dari kelima strategi advokasi tersebut, pada akhirnya memiliki sisi kekuatan dan kelemahan untuk melakukan sebuah gerakan sosial dalam mempengaruhi kebijakan revisi UU KPK yang namun pada akhirnya strategi advokasi yang dilakukan oleh koalisi masyarakat sipil antikorupsi tidak berhasil mempengaruhi para pemangku kebijakan dan pada tahun 2019, UU mengenai KPK telah direvisi pada 17 September 2019 .
\end{abstract}

\section{Tentang:}

M. Ezha Fachriza Roshady, merupakan mahasiswa S-2 di Magister Ilmu Politik Universitas Indonesia pada tahun 2021.

Sri Budi Eko Wardhani telah menyelesaikan studi S-3 di Pasca Sarjana Doktoral Ilmu Politik Universitas Indonesia. Penulis saat ini bekerja sebagai Sekretaris Prodi Program Pasca Sarjana Ilmu Politik Universitas Indonesia. 


\section{PENDAHULUAN}

Pembentukan Komisi Pemberantasan Korupsi (KPK) merupakan hal yang sejalan dengan setting demokrasi sebagaimana dicita-citakan agenda Reformasi sejak 1998, ketika Indonesia menghadapi krisis finansial yang berakhir pada krisis multidimensial menjadi faktor utama yang berkaitan dengan pemberantasan korupsi. Di satu sisi, ada usaha untuk mendorong terjadinya perubahan karakter kekuasaan dari otoriter menuju demokrasi. Di sisi lainnya, ada upaya untuk membangun rezim hukum antikorupsi dari berbagai aspeknya. Salah satu isu utama yang menjadi agenda gerakan reformasi dan sekaligus menjadi perhatian publik adalah pembentukan pemerintahan yang bersih dan bebas dari KKN penuntasan berbagai kasus korupsi yang menjadi bagian dari rezim otoritarian Orde baru, pembangunan sistem, dan upaya untuk meminimalisir berbagai potensi korupsi pada pemerintahan yang akan datang (Widjajanto dan Hadjar, 2020), oleh karena itu KPK merupakan amanat dari reformasi yang perlu didukung oleh semua pihak, khususnya kelompok masyarakat sipil yang telah berhasil mendorong terbentuknya UU KPK.

Sejak Komisi Pemberantasan Korupsi (KPK) berdiri pada tahun 2003 hingga 2018, KPK telah memproses sejumlah 119 kepala daerah tersangka kasus korupsi; 247 anggota lembaga legislatif yang terdiri dari Dewan Perwakilan Rakyat (DPR) dan Dewan Perwakilan Rakyat Daerah (DPRD); 4 orang ketua umum partai politik (parpol); 238 pihak swasta dan 5 kasus yang melibatkan korporasi (Nailufar, 2019). Citra Indonesia di mata dunia pun tidak menunjukkan perbaikan signifikan mengenai pemberantasan korupsi. Indeks Persepsi Korupsi (IPK) yang dipublikasikan Transparency International tahun 2019 menempatkan Indonesia pada peringkat 85 dari total 180 negara, naik sedikit dari tahun 2018 yang berada di peringkat 89 . Bahkan di tahun 2020 IPK Indonesia mengalami penurunan angka dengan nilai 37, dan menduduki posisi 102 dari 180 negara yang disurvei oleh Transparency International. Padahal semangat cita-cita Reformasi pada 1998 bertujuan untuk mewujudkan negara yang terbebas dari berbagai praktik Korupsi, Kolusi dan Nepotisme (KKN) sebagai fokus agenda utama.

Usulan untuk merevisi UU KPK pada 2019 bukan merupakan fenomena yang baru pertama kali terjadi, akan tetapi telah ada sejak periode kedua Presiden Susilo Bambang Yudhoyono menjabat di tahun 2010. Menurut studi Permata (2017), sejak usulan revisi UU KPK pada tahun 2010 hingga tahun 2016 digulirkan oleh DPR maupun Pemerintah, salah satu kelompok masyarakat sipil (Civil Society) yang gencar menolak revisi UU KPK salah satunya ialah ICW (Indonesia Corruption Watch). ICW pada tahun 2010 melakukan berbagai upaya dalam hal mengadvokasi penolakan terhadap wacana revisi UU KPK bersama dengan berbagai kelompok masyarakat yang melakukan gerakan kolektif dengan nama Koalisi Masyarakat Sipil Antikorupsi (Permata, 2017). Strategi advokasi dengan membangun koalisi agar dapat saling berkoordinasi, serta bertukar pikiran dengan individu atau organisasi yang memiliki kesamaan tujuan dikemukakan oleh Gen dan Wright (2013), Koalisi dibentuk juga untuk membangun legitimasi publik terhadap isu yang diadvokasikan. Koalisi tersebut telah terbentuk sejak fenomena kasus KPK dengan Kepolisian Republik Indonesia (Polri) atau yang dikenal dengan fenomena "Cicak Versus Buaya". Kehadiran Koalisi masyarakat sipil antikorupsi bertujuan untuk menolak revisi UU KPK karena dianggap salah satu bentuk pelemahan terhadap KPK secara kelembagaan (Permata, 2017).

Wacana pertama sejak 2010 memiliki dinamika cukup panjang, misalnya pada 16 Desember 2011 DPR menyepakati 644 RUU termasuk RUU KPK yang menjadi pembahasan dalam agenda program prioritas legislasi nasional (prolegnas) tahun 2012. Pada 4 Oktober 2012 Komisi III DPR sepakat melanjutkan revisi UU KPK. Kemudian pada 16 Oktober 2012 kesepakatan itu berakhir dengan putusan Panitia Kerja (Panja) revisi UU KPK akibat desakan oleh kelompok masyarakat sipil, sehingga beberapa Fraksi DPR yang sebelumnya mendukung revisi, setelah terjadinya gerakan dari kelompok masyarakat sipil berubah

M. Ezha Fachriza Roshady \&Sri Budi Eko Wardhani 
menjadi menolak. Sidang paripurna berlangsung dengan putusan yaitu revisi UU KPK dibatalkan (Rastika, 2019).

Pada era pemerintahan Presiden Joko Widodo, tepatnya 23 Juni 2015, diadakan rapat paripurna DPR untuk memasukkan kembali revisi UU KPK ke prolegnas. Namun pada 7 Oktober 2015 terdapat penolakan oleh KPK terkait wacana DPR yang akan memasukkan kembali agenda revisi UU KPK ke prolegnas, bahkan Ketua KPK Agus Rahardjo mengancam akan mengundurkan diri jika wacana tersebut tetap dilanjutkan DPR maupun Pemerintah. Sehingga pada 11 Februari 2016 ada pembatalan agenda rapat di DPR untuk membahas revisi UU KPK dikarenakan Fraksi Gerindra dan Demokrat menolak wacana tersebut. Ketika muncul wacana revisi, koalisi melakukan berbagai upaya dalam memobilisasi publik menjadi sebuah gerakan. Misalnya pada wacana revisi UU KPK tahun 2015, Koalisi Masyarakat Sipil melakukan beberapa aksi mobilisasi publik, di antaranya aksi membangun 'Museum KPK' (8 Oktober 2015); Aksi Kentongan (16 Februari 2016); memberikan replika korek kuping raksasa kepada anggota DPR RI dari Fraksi Gerindra Martin Hutabarat (17 Februari 2016); aksi damai menolak rencana revisi UU Nomor 30 tahun 2002 tentang Komisi Pemberantasan Tindak Pidana Korupsi (22 Februari 2016); dan mengumpulkan tanda tangan Guru Besar pada 21 Februari 2016 (Permata, 2017).

Pada 10 Januari 2017, DPR menetapkan prolegnas yang terdiri atas 50 RUU. Namun, revisi UU KPK tidak termasuk di dalamnya karena Pemerintah menyatakan akan menarik diri dari pembahasan jika revisi bertujuan untuk memperlemah KPK. Komitmen tersebut muncul pada 15 Februari 2018 melalui Bambang Soesatyo selaku Ketua DPR yang memastikan bahwa DPR tidak akan mendorong rekomendasi revisi UU KPK. Akan tetapi setahun setelahnya komitmen tersebut dilanggar. Pada 2019, wacana revisi UU KPK secara tiba-tiba, tanpa sepengetahuan koalisi masyarakat sipil antikorupsi, dilakukan proses pembahasan secara cepat dalam kurun waktu 14 hari sejak wacana mengemuka hingga disahkan melalui Rapat Paripurna DPR RI pada 17 September 2019. Revisi atas UU Nomor 30 Tahun 2002 telah disepakati DPR bersama Pemerintah. Revisi tersebut terjadi di tengah protes keras dari berbagai kelompok masyarakat, salah satunya ialah koalisi masyarakat sipil antikorupsi yang terdiri dari berbagai elemen, di antaranya Indonesia Corruption Watch (ICW), Yayasan Lembaga Bantuan Hukum Indonesia (YLBHI), Pusat Studi Hukum Kebijakan (PSHK), Kelompok Mahasiswa dan Pelajar hingga berbagai akademisi dan lembaga dari berbagai perguruan tinggi di Indonesia (Fahmilda \& Prastiyono, 2019).

Perdebatan pada tahun 2019 bagi koalisi, pelemahan terhadap KPK terdapat di dalam point draft usulan perubahan UU KPK yang diusulkan oleh DPR, yaitu melalui berbagai pasal yang dianggap bukan untuk memperkuat KPK, akan tetapi kebalikannya. Hal tersebut tercantum pada draft rancangan revisi UU KPK yang menjelaskan bahwa KPK masuk ke dalam struktur kekuasaan eksekutif, hal tersebut justru akan memperlemah independensi KPK yang seharusnya menjadi lembaga yang independen terlepas dari struktur kekuasan negara. Hadirnya kelembagaan baru seperti Dewas KPK yang memiliki kewenangan berlebih, kewenangan KPK untuk menerbitkan SP3, Alih Status Pegawai KPK menjadi ASN hingga menutup kemungkinan KPK membentuk lembaga perwakilan di daerah, padahal kasus korupsi besar banyak ditemukan hingga ke berbagai daerah di seluruh Indonesia (Ramadhana \& Oktaryal, 2020). Atas dasar permasalahan tersebut, kelompok masyarakat sipil membentuk aksi kolektif dalam mendesak DPR dan Pemerintah untuk membatalkan niat untuk merevisi UU KPK dengan melakukan gerakan sosial.

Berdasarkan permasalahan yang telah diuraikan, maka penulis mengangkat tema tersebut untuk dilakukan telaah lebih dalam, menggali informasi mendalam dan menganalisa sejauh mana Koalisi Masyarakat Sipil Antikorupsi berusaha bergerak dalam mengadvokasi desakan untuk membatalkan revisi UU KPK pada tahun 2019. Penelitian ini juga memiliki tujuan untuk mengetahui strategi advokasi yang dilakukan oleh kelompok masyarakat sipil yang tergabung dalam sebuah kekuatan gerakan kolektif yaitu koalisi antikorupsi, selain itu 
penelitian ini mengidentifikasi kelompok masyarakat sipil sebagai kelompok penekan yang berada di luar pemerintahan dalam mempengaruhi segala bentuk proses legislasi yang dilakukan oleh pemangku kebijakan dalam hal ini legislasi mengenai pemberantasan korupsi yang hari ini masih menjadi persoalan serius di Indonesia. Atas dasar permasalahan tersebut, peneliti mencoba merumuskan pertanyaan yaitu: Bagaimana strategi advokasi yang dilakukan koalisi masyarakat sipil antikorupsi pada tahun 2019 dalam mendesak pembatalan revisi Undang-Undang Nomor 30 Tahun 2002 tentang KPK.

\section{METODE PENELITIAN}

Metode kualitatif digunakan untuk menjawab pertanyaan penelitian ini, dengan menggunakan metode kualitatif tujuan dan kebutuhan penelitian ini dapat terpenuhi. Creswell memaparkan bahwa untuk menjawab pertanyaan "Bagaimana" kecocokan untuk dapat memaknai penyebab sebuah kondisi atau peristiwa politik yang terjadi (Creswell, 2010). Peneliti mengumpulkan berbagai data antara lain data primer dan data sekunder, data primer didapatkan melalui proses wawancara yang peneliti lakukan dengan para narasumber yang berkaitan dengan topik permasalahan penelitian, kemudian direkam dan dicatat oleh peneliti (Sarwono, 2006). Teknik analisis yang digunakan menjelaskan data yang diperoleh dari hasil wawancara sebagai data primer, yang selanjutnya direduksi dan dimasukkan ke dalam pola, kategori, fokus, atau tema tertentu yang sesuai (Faisal, 2010).

Setelah memperoleh data mengenai permasalahan dan strategi advokasi yang dilakukan oleh koalisi dalam melakukan penolakan terhadap revisi UU KPK, maka dianalisis menggunakan teori mengenai advokasi gerakan. Metode penentuan responden dalam wawancara yang digunakan ialah teknik kesesuaian, yaitu teknik pemilihan informan yang dianggap sesuai oleh peneliti (Sarwono, 2006). Informan dalam hal ini tentunya pihak dari koalisi masyarakat sipil antikorupsi seperti Kurnia Ramadhana sebagai Divisi Hukum ICW, Asfinawati Direktur YLBHI, Bivitri Susanti dari PSHK, Wawan Suyatmiko dari Transparancy International Indonesia (TII). Selanjutnya merupakan data sekunder dengan melalui studi dokumen, yaitu dengan mengumpulkan data atau informasi dengan cara membaca surat, pengumuman, ikhtisar rapat, pernyataan tertulis kebijakan tertentu, dan berbagai bahan penelitian lain (Sarwono, 2006). Berbagai dokumen tersebut dapat berupa koran cetak maupun elektronik, laporan kantor, makalah; ataupun dokumen privat seperti buku harian, diary, surat, email (Creswell, 2010). Contoh dokumen-dokumen yang digunakan diantaranya berupa pasal-pasal yang terkandung di dalam UU. Nomor 30 tahun 2002 tentang KPK serta perubahan keduanya UU. Nomor 19 tahun 2019, dan juga bentuk dokumen lainnya yang berguna untuk menambah dan memperkuat data-data yang tidak diperoleh dari observasi.

\section{HASIL DAN PEMBAHASAN}

Koalisi masyarakat sipil antikorupsi memperjuangkan tuntutan dalam upaya mendesak revisi UU KPK tidak dilakukan dengan melakukan beberapa strategi advokasi. Adapun urutan strategi advokasi yang dilakukan koalisi terhadap revisi UU KPK sejalan dengan pendekatan teori advokasi masyarakat sipil yang dikemukakan oleh Gen \& Wright (2013) yaitu dengan melakukan penelitian atau kajian akademik; melakukan lobi dan membangun hubungan dengan pembuat kebijakan; membangun framing; melakukan liputan media; serta kelompok masyarakat sipil yang tergabung ke dalam koalisi mencoba untuk memperluas jejaring dalam melakukan gerakan sosial sebagai salah satu strategi advokasi dalam menolak usulan revisi UU KPK pada tahun 2019. 


\section{Melakukan Kajian atau Analisis Kebijakan}

Strategi advokasi yang dilakukan koalisi terhadap revisi UU KPK yang pertama ialah melakukan penelitian atau analisis kebijakan. Selain melobi pemerintah, koalisi juga melakukan penelitian atau analisis kebijakan. Hal ini sejalan penelitian Ridwan (2012), dimana tipe LSM advokasi yang kesibukan utamanya adalah membuat pengumpulan data dan riset terhadap isu korupsi dan dilanjutkan dengan melobi pemerintah dan media.

Dalam hal ini Koalisi Masyarakat Sipil Antikorupsi membuat kajian revisi UU KPK, yang didalamnya menemukan poin-poin yang lebih mendorong upaya pelemahan KPK daripada memperkuat KPK. Kajian yang dilakukan oleh koalisi tentu mengundang para ahli (expert) untuk dihadirkan dalam mengkritisi revisi UU KPK. Isi dari kajian tersebut ialah analisis hukum terkait kebijakan dalam hal ini revisi UU KPK serta impilkasinya jika revisi undang-undang KPK disahkan, dan pernyataan sikap koalisi masyarakat sipil mengenai revisi UU KPK. Kajian berbentuk policy paper dan policy brief. Sebagaimana yang dilakukan oleh TII yang masuk ke dalam NGO yang tergabung ke dalam koalisi bahwa TII bekerja di dalam koalisi dan mendukung dari sisi kajian :

"Ketika revisi UU KPK bergulir, kita melakukan berbagai kajian, riset dan sebagainya. Kemudian kajian riset itu digunakan dasar oleh kawan-kawan yang lain untuk mengorganisir kelompok-kelompok yang lain untuk terlibat lebih inklusif, atau dengan ICW misalnya yang advokasi di bagian media gitu ya, atau mungkin temanteman jaringan player yang ikut melakukan pembelaan, bagi beberapa staf personel dan sebagainya saat dilakukan kriminalisasi. Jadi TI lebih kearah membuat kajian atau riset terkait bagaimana revisi UU KPK, dan tentunya karena kami fokusnya di riset, kami juga banyak bekerja sama dengan pusat kajian, Pusat kajian antikorupsi (Pukat UGM), pusat kajian konstitusi (Pusako Andalas) dan sebagainya terkait hal ini." (Wawancara Wawan Suyatmiko 18 Maret 2021).

Ketika ingin melakukan kajian terhadap permasalahan revisi UU KPK, koalisi masyarakat sipil antikorupsi sempat mengalami kendala untuk mendapatkan draft rancangan revisi. Kemudian meminta pada KPK yang juga tidak mendapatkan secara resmi draft dari DPR, dan Kemenkumham untuk mencari draft tersebut, sebagaimana dikatakan Direktur Transparancy International Indonesia :

"Koalisi masyarakat sipil sendiri dalam melakukan kajian draft yang beredar, karena sejujurnya bahkan KPK sendiri saja tidak mendapatkan draft resmi dari DPR dan Kemenkumham, sehingga kami koalisi dan juga dengan KPK, karena KPK waktu itu masuk dalam kualifikasi, bahkan walaupun dia lembaga negara masuk dalam koalisi, sehingga kami mendesak, mendorong KPK untuk mencari draftnya, karena bagaimanapun juga draft ini yang penting. Kemudian kami melakukan kajian begitu ya, kajian-kajian dan kemudian dari kajian-kajian ditemukan sejumlah pasal yang melemahkan. Kalau menurut kajian baik itu dari berbagai sumber termasuk dalam TI, Pukat dan KPK sendiri tuh menemukan ada 26 pasal yang melemahkan KPK atau yang mengubah KPK menjadi tidak powerfull lagi, sehingga dari situ kita melakukan kajian yang lebih detail dan mengadvokasikan bahwa itulah yang membuat KPK hari ini menjadi tidak se-power yang sebelum direvisi" (Wawancara Wawan Suyatmiko 18 Maret 2021).

\section{Melakukan Lobi dengan Pemerintah dan DPR}

Strategi advokasi selanjutnya yang dilakukan koalisi masyarakat sipil antikorupsi yaitu melakukan lobi kepada Anggota DPR Periode 2014 - 2019 khususnya di Komisi III, seperti Trimedya Pandjaitan (Fraksi PDI-Perjuangan). Selain itu koalisi juga melakukan audiensi serta membangun hubungan komunikasi dengan pemerintah melalui Kementerian Hukum 
dan HAM mengenai penolakan terhadap revisi UU KPK yang diinisiasikan oleh DPR RI pada tahun 2019.

"Iya, kita menggunakan itu (berkomunikasi ke Pemerintah), kita bertemu dengan beberapa orang membahas capim, soal revisi, tapi ngga berbuah apa-apa. Jadi mereka juga tidak bisa bergerak banyak dan jaringannya NGO itu kan bukan key person dalam partai politik, karena itu ketua umum. Jadi mungkin keinginan kita sama ya, tapi tidak punya kekuatan untuk melawan itu." (Wawancara dengan Kurnia Ramadhana (ICW) pada 3 Maret 2021).

Hal senada juga diungkapkan Perwakilan TII yang juga terlibat di dalam koalisi, bahwa pertama koalisi telah melakukan berbagai upaya berkomunikasi dengan pihak-pihak di dalam maupun di luar pemerintahan, namun pola komunikasi hanya sebatas di lingkup kecil jejaring anggota DPR yang dimiliki oleh koalisi saja dan umumnya para anggota DPR tersebut ialah mantan aktivis dari kelompok masyarakat sipil, bukan kepada pimpinan partai politik. Selain itu koalisi masyarakat sipil antikorupsi sangat menyayangkan orientasi yang dimiliki oleh para mantan aktivis yang kini menduduki posisi di eksekutif maupun legislatif telah minim idealisme untuk turut melakukan penolakan terhadap revisi UU KPK.

"Hari ini ketika KPK dilemahkan mereka cukup diam saja, enggak banyak bergerak, dengan alasan kami kalah, jadi benar mereka sudah tunduk pada oligarki. Akhirnya mentoknya mereka akan bilang ada oligarki yang baik, ada oligarki yang jelek. Bilang saja orientasinya sudah ke kekuasaan, selesai. Jadi, sudah tidak usah lagi membawa nama-nama mantan aktivis gitu loh" (Wawancara dengan Wawan Suyatmiko pada 18 Maret 2021).

Pasca disahkannya revisi UU No. 30 Tahun 2002 yang bertepatan pada 17 September 2019 terdapat aksi dari kelompok mahasiswa Fakultas Hukum Universitas Indonesia (FH UI) yang reaktif untuk mendaftarkan judicial review ke Mahkamah Konstitusi terkait direvisinya UU KPK. Namun, menurut salah satu mahasiswa FH UI memberikan keterangan pada penulis bahwa ia sempat disarankan oleh seorang pegiat antikorupsi dari ICW untuk menunda proses judicial review ke MK dikarenakan koalisi masyarakat sipil antikorupsi ingin mencoba melakukan lobi politik kepada Presiden untuk mengeluarkan Perppu terkait pengesahan revisi UU KPK yang terjadi 17 September 2019.

"Jadi saat itu kita menyuarakan Perppu ke Presiden, karena itu sudah disahkan dan tinggal diundangkan tanggal 17 Oktober. Presiden mengundang berbagai tokoh hukum, itu ada puluhan orang ada beberapa mantan pimpinan KPK juga dan sempat mengutarakan, ingin mengeluarkan Perppu. Maka dari itu strategi kami kemarin tidak langsung mengajukan JR, agar Presiden tidak punya legitimasi untuk menolak Perppu tersebut. Ternyata ada teman-teman mengajukan JR ke MK, iya kita ya ngga sepakat dengan strategi mereka. Jadi dugaan kita benar, ketika mereka daftarkan JR itu, itu langsung direspon oleh pemerintah tidak perlu lagi Perppu karena sudah ada yang JR, kita kembalikan ke persidangan di MK.’(Wawancara dengan Kurnia Ramadhana).

Dalam melakukan strategi advokasi, koalisi masyarakat sipil antikorupsi sulit membendung pola gerakan yang juga dilakukan oleh masyarakat secara luas. Contohnya dari kalangan Mahasiswa FH UI yang telah reaktif mendaftarkan judicial review revisi UU KPK ke MK, padahal secara teknis belum ada penomoran terhadap revisi UU KPK, sehingga

M. Ezha Fachriza Roshady \&Sri Budi Eko Wardhani 
membuat kurang terkoordinasinya antara gerakan koalisi dengan gerakan masyarakat di luar koalisi.

"Iya, berarti kita tidak bisa kontrol, karena menjadi isu nasional. Salah satu kelemahan koalisi, karena susah kan ya kalau kita kontrol. Kalau dikontrol anak-anak UI atau masyarakat biasa misalnya, atau pemerintah menyiapkan pemohon-pemohon tertentu agar bisa menjadi legitimasi mereka. Kita sudah mengingatkan persuasi, tapi ternyata mereka tetap bersikeras.” (Wawancara dengan Kurnia Ramadhana).

Pada usulan revisi UU KPK tahun 2019 ruang gerak koalisi untuk membangun komunikasi dengan legislatif dan eksekutif sangat dibatasi, tidak adanya undangan rapat dengar pendapat dan proses kilat yang dilakukan oleh DPR RI membuat koalisi tidak mudah untuk mendesak dan melobi pihak DPR yang sengaja tidak melibatkan peran serta koalisi masyarakat sipil agar upaya untuk menggoalkan revisi UU KPK berjalan dengan mulus tanpa ada hambatan, hal ini menjadi pembeda dari strategi advokasi yang dilakukan oleh koalisi pada usulan revisi UU KPK tahun-tahun sebelumnya.

\section{Melakukan Framing}

Selain melobi pemerintah dan DPR, koalisi masyarakat sipil antikorupsi yang terdiri dari berbagai kelompok masyarakat sipil yang bergerak sebagai LSM advokasi juga melakukan lobi atau membangun hubungan dengan media. Mengacu kepada McAdam dan Snow (1997) fungsi dari frame untuk dapat memahami suatu peristiwa atau keadaan, yaitu mengorganisasi pengalaman dan memandu tindakan, baik individu atau kolektif. Sebagai pemahaman, frame merupakan tindakan kolektif yang memusatkan perhatian pada situasi tertentu yang dianggap bermasalah, membuat atribusi mengenai siapa atau apa yang harus disalahkan, dan dengan kata lain, fungsi utama frame dalam tindakan kolektif merupakan bagian dari usaha pengikut gerakan untuk menegosiasikan pemahaman tentang beberapa kondisi atau situasi bermasalah yang mereka definisikan sebagai kebutuhan akan perubahan, keterkaitan mengenai siapa atau apa yang harus disalahkan, ungkapkan beberapa pengaturan alternatif, dan dorong orang lain untuk bertindak secara bersamaan untuk mempengaruhi perubahan (Benford dan Snow, 2000).

Terkait revisi UU KPK tahun 2019, pesan yang di-framing oleh koalisi masyarakat sipil antikorupsi adalah telah terjadinya upaya untuk melemahkan lembaga pemberantasan korupsi melalui revisi undang-undang yang akan disahkan DPR bersama Pemerintah. Bagi koalisi terdapat 6 permasalahan yang telah penulis jelaskan sebagai pengantar dalam bab ini. Kemudian pada saat revisi UU KPK tahun 2019, koalisi turut membentuk hashtag dukungan seperti \#SaveKPK dan \#reformasidikorupsi untuk dapat dipublikasikan ke masyarakat luas. Tujuan framing dengan menggunakan hashtag, agar dapat diterima publik secara mudah. Mengapa menggunakan redaksi \#reformasidikorupsi, karena pada era Reformasi ini agenda pemberantasan korupsi telah mengalami kemunduran, melemahkan KPK adalah tindakan yang tidak sejalan dengan semangat cita-cita reformasi yang digaungkan oleh para aktivis tahun 1998.

Dalam melakukan framing gerakan, koalisi tidak ingin membesar-besarkan nama forum koalisi masyarakat sipil antikorupsi yang menjadi wadah mereka dalam melakukan langkah advokasi, hal tersebut bertujuan dapat mudah digunakan oleh publik agar mau turut serta terlibat terhadap isu ini dan tidak menimbulkan kecemburuan sosial di antara kelompok masyarakat yang juga ingin turut serta mendesak revisi UU KPK untuk dibatalkan.

"Kalau saya sih justru melihat sebenarnya dahulu kenapa sebagai koalisi tidak terlalu dibesar-besarkan, karena ingin isu ini jadi milik semua orang, makanya yang dibesarbesarkan adalah tagar \#reformasidikorupsi. Jadi kami justru merasa, kalau nama 
koalisi yang dibesarkan, maka nanti jadinya tidak ada rasa kepemilikan. Jadi mungkin kawan-kawan yang mengorganisir Gejayan Memanggil, saya kan bukan anggota koalisi jadi kayak struktural banget gitu loh. Jadi kita justru menginginkan koalisi cair, jadi kalaupun ada yang muncul, itu dibiarkan muncul sendiri-sendiri bahkan tidak hanya dari LBH, ICW bahkan Irma dari Efek Rumah Kaca jalan sendiri juga, mereka bikin juga ya banyak tuh sebenarnya mereka. Terus kan wartawan jalan sendiri juga, tapi yang jelas waktu itu memang kami sengaja tidak mau memonopli. Bahwa kami loh koalisi yang ngerjain ini, itu karena kalau dimonopoli nanti malah isunya nggak bisa, nggak bisa diambil sama semua orang jadi inklusif gitu. Akhirnya masing-masing bebas aja walaupun kami tetep rapat tetep berkabar di WhatsApp group." (Wawancara dengan Bivitri Susanti (PSHK), 5 Maret 2021).

Pada wacana revisi UU KPK tahun 2019 sempat timbul framing bahwa KPK telah disusupi kelompok Taliban dan beberapa hashtag yang digunakan seolah-olah KPK telah melakukan tindakan yang kurang profesional atau sewenang-wenang. Hal tersebut dilakukan di jagad sosial media maupun tokoh-tokoh pendukung pemerintah dan melalui pemberitaan tersebut sempat membuat gaduh publik. Ketika ditanyakan efektif atau tidaknya framing yang dilakukan oleh koalisi, Direktur Yayasan LBH Indonesia Asfinawati mengatakan:

"Kalau melihat publik yang bergerak itu kan efektif sekali meskipun pertarungannya menurut saya bukan pada rilis resmi itu, pada akhirnya. Tapi di media sosial ya karena sebetulnya publik itu terutama yang kelas menengah ke atas itu di perkotaan yang selama ini bulat membela KPK itu kan terbelah gara-gara isu tadi, taliban dan lainlain. Jadi sebetulnya di medsos itu yang masih perlu."

Framing di sosial media masih sangat diperlukan dan strategi untuk menghadapi berbagai isu tersebut membuat konsentrasi koalisi terganggu dikarenakan melalui penggiringan opini tersebut dapat membuat langkah DPR maupun Pemerintah mempermudah mendapat perhatian dari publik untuk mempercepat revisi UU KPK. Koalisi masyarakat sipil antikorupsi tidak terlalu cepat merespon isu penggiringan opini yang dituduhkan kepada KPK pada saat itu, dan sulit melawan berbagai buzzer yang bergerak secara sporadis melalui media sosial.

\section{Melakukan Liputan Media}

Liputan media mengenai mengenai isu-isu kebijakan menurut Linsky (1998), dapat mengangkat isu ke tingkat pembuat kebijakan yang lebih tinggi dan memicu kemauan politik mereka untuk bertindak dalam isu-isu ini (Gen \& Wright, 2013). Dalam hal ini, liputan media dapat meningkatkan kemauan politik para pembuat kebijakan untuk menanggapi atau bertindak terhadap isu-isu tersebut. Koalisi secara intens melakukan advokasi terhadap revisi UU KPK melalui media, yaitu melakukan press conference serta menaikkan isu penolakan revisi UU KPK di berbagai akun media sosial masinng-masing simpul organisasi yang ada di dalam koalisi.

TII bersama ICW melakukan pemberitaan media terkait pelemahan revisi UU KPK hingga pemberitaan tersebut sampai kepada masyarakat global dan direspons oleh $25 \mathrm{NGO}$ pegiat anti korupsi dari berbagai negara yang tergabung ke dalam UNCAC Coalition (UN Convention Against Corruption) dengan menandatangani pernyataan sikap yang berjudul "UNCAC Coalition Statement on threats to the independence of Indonesia's Corruption Eradication Commission KPK” yang dirilis pada 27 September 2019, 10 hari sejak UU KPK direvisi oleh DPR.

M. Ezha Fachriza Roshady \&Sri Budi Eko Wardhani 
"Peran yang dimainkan oleh TII melakukan upaya penggalangan advokasi di lintas negara karena kita Transparansi Internasional Indonesia bagian dari Transparansi Internasional Global sehingga kita banyak jaringan global, hasil advokasi atau proses advokasi kita kabarkan ke dunia luar sehingga masyarakat di luar sana, juga tahu bahwa hari ini, misalnya terjadi upaya pelemahan KPK melalui revisi undang-undang KPK tersebut. Dua peran itu yang paling banyak dilakukan TII dalam koalisi." (Wawancara dengan Wawan Suyatmiko pada 18 Maret 2021).

Meski strategi yang dilakukan oleh koalisi masyarakat sipil antikorupsi telah berhasil mendapatkan dukungan yang positif dari berbagai media nasional maupun internasional, akan tetapi dukungan tersebut tidak membuat goyah langkah DPR untuk tetap mengesahkan revisi UU KPK dan Presiden Joko Widodo juga tidak kunjung mengeluarkan Perppu atas revisi yang telah diparipurnakan pada 17 September 2019.

\section{Memperluas Jejaring dalam Melakukan Gerakan Sosial}

Strategi advokasi yang kelima ialah memperluas jejaring dalam melakukan gerakan sosial, sebagai mana yang dijelaskan oleh Gen \& Wright (2013) strategi advokasi sebagaimana puncaknya yaitu kelompok gerakan dapat mengajak atau memaksa masyarakat untuk memilih, melakukan demonstrasi, protes, dan lain-lain. Terkait revisi UU KPK pada tahun 2019, koalisi masyarakat sipil antikorupsi melakukan mobilisasi jaringan seperti YLBHI dengan memanfaatkan sumber daya yang dimiliki untuk melakukan aksi unjuk rasa. Aksi unjuk rasa yang hampir kurang lebih sepuluh kali dilakukan di Halaman Gedung KPK, selanjutnya pada 13 September 2019 misalnya terjadi aksi tabur bunga di Halaman Gedung KPK yang dilakukan oleh puluhan peserta aksi yang terdiri dari anggota koalisi masyarakat sipil antikorupsi dan berbagai aksi unjuk rasa lainnya saat mendekati paripurna dan setelahnya dengan memperluas jejaring bersama para buruh dan mahasiswa.

"Ketika kita tahu bahwa hari ini terjadi yang namanya shrinking democracy in public space, maka turun ke jalan, aksi massa yang kemarin dilakukan oleh koalisi secara inklusif dengan gerakan yang lain itu menjadi satu-satunya cara yang bisa kita gunakan hari ini, karena advokasi yang dilakukan ke DPR juga mentok atau advokasi yang dilakukan ke istana dalam hal ini, yang mantan-mantan aktivis, yang dulunya juga demonstran itu juga mentok juga, ternyata nggak punya visi yang sama. Apa yang bisa kita lakukan begitu, ya sudah, satu-satunya jalan hari ini yang bisa kita lakukan adalah merebut kembali ruang-ruang demokrasi dengan cara turun ke jalan, itu saja masih tidak didengarkan. Maksud saya ini juga bukan karena suara koalisi kurang kencang, bukan, tapi kepentingan penguasa, untuk agenda kepentingan penguasa untuk melemahkan KPK itu yang lebih dominan hari ini karena mereka punya kekuasaan, itulah yang lebih dominan dan kemudian itu menjadikan kenapa revisi undang-undang KPK mulus berjalan hanya dalam waktu dua pekan" (Wawancara dengan Wawan Suyatmiko pada 18 Maret 2021).

Selain melakukan berbagai aksi unjuk rasa, koalisi dalam memperluas jejaring juga melakukan penggalangan dukungan publik melalui petisi daring (online) yang termuat dalam situs change.org, bahkan petisi daring bertemakan penolakan revisi UU KPK merupakan petisi terbanyak yang ditanda tangani oleh publik sepanjang tahun 2019. Petisi-petisi terkait gerakan \#ReformasiDikorupsi terangkum dalam laman reformasidikorupsi-change.org dan berhasil menggalang lebih dari 2,3 juta suara dari total 8 petisi.

"Tahun 2019 gerakan sosial pada platform digital Change.org juga diramaikan kampanye bertemakan demokrasi dan antikorupsi. Gerakan sosial terkait demokrasi 
dan antikorupsi meningkat karena situasi politik di Indonesia yang juga sedang diuji. Mulai dari pergantian masa jabatan wakil rakyat hingga dinamika pemilihan presiden dan wakil presiden." (Pernyataan Desmarita Murni yang dikutip dalam pemberitaan Kabar24bisnis.com pada 18 Januari 2020).

Tidak cukup dengan menggalang opini publik, koalisi masyarakat sipil antikorupsi juga memerlukan dukungan dari para akademisi, guru besar, pakar dan tokoh pegiat antikorupsi. Ketika koalisi sedang memperluas jejaring, koalisi juga dihadapkan dengan pembelahan opini di tengah-tengah masyarakat bahwa penggiringan isu terhadap KPK bertindak sewenang-wenang dan KPK telah disusupi Kelompok Taliban merupakan persoalan serius yang koalisi sendiri tidak bisa mengcounter permasalahan tersebut.

Dalam melakukan advokasi menyusun strategi gerakan, koalisi masyarakat sipil antikorupsi melakukannya dengan pola tergantung pada situasi dan kondisi saat itu, sebagaimana yang dikatakan oleh Bivitri (2021) sikap kehati-hatian perlu dikedepankan karena tantangan untuk disadap dan terbaca oleh pihak-pihak yang dapat merugikan kerjakerja koalisi perlu diantisipasi,

"Tergantung isunya, jadi kalau yang dibahas isunya sensitif banget kami tutup banget karena kami paham betul bahayanya. Jadi bahkan kalau memang sudah sesuatu yang sifatnya yang sangat teknis mau aksi segala macam itu semua harus mematikan Handphone. Karena upaya penyadapan, upaya penangkapan segala macem itu banyak ya kan termasuk saya sendiri, berapa kali dicoba dan seterusnya. Jadi kami lebih aware, apalagi teman-teman dari ICW sama YLBHI itu mereka yang sangat peka. Nah tapi tentu saja kalau memang rapat terbuka diskusi ya kan yang dibicarakan pada hal-hal yang sifatnya umum kaya terbuka. Tapi umumnya memang tertutup karena serius kali ini yang lagi dilawan."

Dari uraian mengenai strategi advokasi yang dilakukan koalisi masyarakat sipil antikorupsi pada tahun 2019, umumnya strategi yang dilakukan hampir sama seperti advokasi pada usulan revisi UU KPK di tahun-tahun sebelumnya. Hanya saja pada tahun 2019, gerakan koalisi menemukan berbagai peluang dan hambatan sehingga terdapat strategi yang memiliki kekuatan dan kelemahan ketika koalisi melakukan strategi gerakan. Maka pada pembahasan selanjutnya, penulis memetakan kekuatan dan kelemahan strategi advokasi koalisi masyarakat sipil antikorupsi sebelum akhirnya dapat mengidentifikasi faktor penyebab kegagalan gerakan sosial yang dilakukan oleh koalisi masyarakat sipil antikorupsi pada tahun 2019.

\section{Kekuatan dan Kelemahan Strategi Advokasi Koalisi Masyarakat Sipil Antikorupsi dalam Menolak Revisi Undang-Undang Nomor 30 Tahun 2002 Tentang Komisi Pemberantasan Tindak Pidana Korupsi}

Pola advokasi yang dilakukan koalisi masyarakat sipil antikorupsi pada 2019 dengan melakukan strategi advokasi yang tidak jauh berbeda dilakukan pada wacana revisi UU KPK di beberapa tahun sebelumnya. Usulan untuk merevisi UU KPK telah diwacanakan oleh DPR sejak 2010 dan muncul kembali pada 2015, dan pada akhirnya mendapatkan momentum pada tahun 2019. Biasanya strategi advokasi yang dilakukan oleh koalisi masyarakat sipil antikorupsi berhasil untuk mendesak pemangku kebijakan untuk membatalkan revisi UU KPK. Untuk itu sebelum penulis menguraikan kelebihan dan kelemahan strategi advokasi yang dilakukan oleh koalisi masyarakat sipil antikorupsi, penulis mengidentifikasi terlebih dahulu berbagai strategi advokasi yang dilakukan oleh koalisi ke dalam tabel berikut.

M. Ezha Fachriza Roshady \&Sri Budi Eko Wardhani 
Tabel 1 Identifikasi Strategi Advokasi Koalisi Masyarakat Sipil Antikorupsi

\begin{tabular}{|c|c|}
\hline Bentuk Advokasi & Tujuan \\
\hline $\begin{array}{l}\text { Melakukan Kajian atau Analisis } \\
\text { Kebijakan }\end{array}$ & $\begin{array}{l}\text { Mengidentifikasi draft rancangan } \\
\text { undang-undang yang dapat berdampak } \\
\text { pada pelemahan independensi KPK }\end{array}$ \\
\hline $\begin{array}{l}\text { Melakukan Lobi } \\
\text { Pemerintah dengan DPR }\end{array}$ & $\begin{array}{l}\text { Membangun komunikasi dan dapat } \\
\text { merubah sikap para pemangku kebijakan } \\
\text { untuk mendukung penolakan terhadap } \\
\text { revisi UU KPK }\end{array}$ \\
\hline Membangun Framing & $\begin{array}{l}\text { Menciptakan narasi kepada masyarakat } \\
\text { luas bahwa pelemahan terhadap KPK } \\
\text { nyata terjadi melalui revisi UU KPK dan } \\
\text { memantik masyarakat untuk turut } \\
\text { mendukung gerakan yang dilakukan oleh } \\
\text { koalisi }\end{array}$ \\
\hline Melakukan Liputan Media & $\begin{array}{l}\text { Mempermudah penyebaran berbagai } \\
\text { pemberitaan mengenai narasi yang } \\
\text { dibuat oleh koalisi dan } \\
\text { menginformasikan sikap pernyataan } \\
\text { yang dikeluarkan oleh koalisi }\end{array}$ \\
\hline $\begin{array}{l}\text { Memperluas Jejaring dalam } \\
\text { Melakukan Gerakan Sosial }\end{array}$ & $\begin{array}{l}\text { Semakin kuatnya konsolidasi dengan } \\
\text { kelompok masyarakat sipil lainnya } \\
\text { dalam melakukan aksi unjuk rasa agar } \\
\text { desakan penolakan revisi dapat segera } \\
\text { didengarkan oleh pemangku kebijakan }\end{array}$ \\
\hline
\end{tabular}

Dari kelima strategi advokasi yang dilakukan oleh koalisi, penulis menganalisis bentuk strategi advokasi terkuat yang dilakukan oleh koalisi. Pertama, mendapatkan dukungan dari berbagai media. Dukungan media kepada gerakan koalisi masyarakat sipil antikorupsi menjadikan berbagai strategi gerakan yang dilakukan oleh koalisi semakin efektif untuk menciptakan narasi kepada publik mengenai berbagai upaya pelemahan dan ancaman terhadap independensi KPK jika revisi UU KPK tetap dilakukan.

Kedua, melakukan kajian dan analisis kebijakan. Koalisi sebelum melakukan berbagai strategi advokasi lainnya tentu melakukan kajian terhadap draft rancangan revisi UU KPK secara mendalam, membahas pasal-pasal yang dapat mengancam independensi KPK dan pasal-pasal yang sekiranya menjadi sebuah kemunduran dalam memberantas korupsi di Indonesia. Tokoh-tokoh aktivis di dalam koalisi masyarakat sipil merupakan tokoh yang mempuni di berbagai kajian isu advokasi dan antikorupsi. Selain itu dalam melakukan berbagai kajian, koalisi menggandeng berbagai guru besar hingga akademisi sehingga dukungan dunia kampus untuk melakukan penolakan terhadap revisi UU KPK semakin kuat.

Tidak hanya memiliki kekuatan yang dijadikan peluang oleh koalisi, koalisi juga mendapati beberapa hambatan dalam menjalankan strategi advokasi menolak revisi UU KPK. Hambatan tersebut diuraikan sebagai berikut. Pertama, dalam melakukan strategi lobi kepada Pemerintah dan DPR, koalisi kurang dapat meyakinkan para pemangku kebijakan seperti Presiden Joko Widodo, Ketua Umum Partai Politik, Para Anggota DPR RI Periode 2014 -2019. Hambatan untuk meyakinkan pihak eksekutif maupun legislatif agar mereka yakin bahwa UU KPK tidak perlu revisi. Startegi lobi yang dilakukan oleh koalisi tidak maksimal sehingga pada akhirnya revisi UU KPK tetap disahkan oleh DPR (wawancara dengan Wawan Suyatmiko, April 2021). 
Kedua, strategi memperluas jejaring dalam melakukan berbagai aksi unjuk rasa. Koalisi masyarakat sipil antikorupsi ketika melakukan advokasi menolak revisi UU KPK, juga mendapatkan berbagai tindakan represif yang dilakukan oleh negara. Peretasan telepon genggam milik anggota koalisi, akademisi, hingga berbagai tokoh yang kritis terhadap revisi UU KPK terjadi. Penyadapan alat komunikasi menjadi sebuah penghambat, dikarenakan terdapat pihak-pihak yang ingin membaca pola dan strategi gerakan yang dilakukan oleh koalisi. Selain itu terjadinya kontra dukungan di masyarakat terhadap revisi UU KPK dengan melakukan aksi unjuk rasa tandingan yang bertujuan untuk memecah konsentrasi gerakan koalisi masyarakat sipil antikorupsi dan memecah perhatian publik terhadap perjuangan yang dilakukan oleh koalisi masyarakat sipil antikorupsi. Bahkan menurut berbagai sumber pemberitaan dan investigasi yang dilakukan oleh Kompas dan Tempo, bahwa peserta unjuk rasa yang mengetahui substansi tuntutan untuk memberikan dukungan terhadap revisi UU KPK di antaranya hanya kordinator lapangannya saja (korlap) paling hanya dua atau tiga orang yang ada di atas mobil, selebihnya peserta aksi yang tidak memahami apa itu perubahan UU KPK dan sebagainya mengenai substansi yang dilakukan melalui aksi unjuk rasa.

Ketiga, strategi pembentukan framing yang dilakukan koalisi tidak mampu membantah isu yang dibingkai oleh kelompok pendukung revisi UU KPK. Ketika koalisi sibuk dengan membingkai narasi pelemahan KPK melalui revisi, koalisi juga dihadapkan dengan berbagai isu mengenai KPK yang sudah over power dan disusupi oleh kelompok Taliban. Hal tersebut menjadi sebuah kelemahan strategi advokasi yang dilakukan oleh koalisi masyarakat sipil karena tidak mampu meng-counter berbagai isu yang beredar di berbagai media sosial yang sejatinya kontra terhadap gerakan yang dilakukan oleh koalisi masyarakat sipil antikorupsi pada tahun 2019.

\section{SIMPULAN}

Aksi kolektif agar gerakan koalisi mencapai tujuan yang dicita-citakan, koalisi masyarakat sipil antikorupsi melakukan beberapa strategi advokasi gerakan yang biasa koalisi lakukan pada setiap desakan menolak revisi UU KPK sejalan dengan konsep metode proses advokasi yaitu melakukan lobi dengan Pemerintah dan DPR, melakukan kajian atau analisis kebijakan, melakukan framing, melakukan liputan media serta memperluas jejaring dalam melakukan gerakan. Koalisi masyarakat sipil antikorupsi dalam melakukan strategi advokasi menolak revisi UU KPK tahun 2019 memiliki kekuatan yang dapat dijadikan peluang kesempatan gerakan koalisi yaitu dukungan dari berbagai media hingga berbagai kajian yang dilakukan didukung oleh para guru besar dan professor sehingga koalisi mendapat dukungan dari dunia kampus. Tidak hanya memiliki kekuatan yang dijadikan peluang, koalisi juga mendapati beberapa hambatan dalam melakukan gerakan mendesak revisi UU KPK untuk dibatalkan. Hambatan tersebut yaitu koalisi kurang meyakinkan para stakeholders, koalisi mendapat perlawanan melalui berbagai cara represif, dibenturkannya gerakan kelompok masyarakat sipil untuk mendukung revisi UU KPK, strategi framing yang dilakukan oleh koalisi tidak mampu membantah isu yang menyerang KPK dan para pegawainya yang dilakukan oleh para pendukung revisi UU KPK melalui sosial media. 


\section{DAFTAR PUSTAKA}

Benford, R. D. \& Snow, D. A.. (2000). Framing Processes and Social Movements: An Overview and Assesment. Annual Review of Sociology, Vol. 26, 611-639. https://doi.org/10.1146/annurev.soc.26.1.611

Creswell, J. W. (2014). Research design: Qualitative, quantitative and mixed methods approaches. London: Sage Publication.

Faisal, S. (2010). Format-Format Penelitian Sosial. Jakarta: Rajawali Pers.

Gen, S., \& Wright, A. C. (2013). Policy Advocacy Organizations: A Framework Linking Theory and Practice. (Journal of Policy Practice, Vol. 12 No.3., h. 18-26. http://dx.doi.org/10.1080/15588742.2013.795477

McAdam, D. \& Snow. (1997). Social Movements:Readings on Their Emergence, Mobilization, and Dynamics. Roxbury Pub.

Nailufar, N. N. (2019). "KPK Fana, Korupsi Abadi (3): Apakah Kita sedang Berjalan Mundur?" https://www.kompas.com/tren/read/2019/10/17/160000165/kpk-fana-korupsiabadi-3-apakah-kita-sedang-berjalan-mundur?page=all

Permata, A. G. (2017). Peran Indonesia Corruption Watch (ICW) dalam Melakukan Advokasi Untuk Mencegah Revisi Undang- Undang No. 30 Tahun 2002. FISIP Universitas Indonesia.

Fahmilda, Y., \& Prastiyono, Y. A. (2019). Representasi, Parodisasi, Dan Kontekstualisasi Tujuh Puluhan Karya Yanusa Nugroho: Pendekatan Posmodernisme Linda Hutcheon. Seminar Internasional Riksa Bahasa.

http://proceedings.upi.edu/index.php/riksabahasa/article/view/1112

Ramadhana, K. \& Oktaryal, A. (2020) Laporan Tim Advokasi Koalisi Masyarakat Sipil Antikorupsi.

Rastika, I. (2019, September 17). Jalan Panjang Revisi UU KPK, Ditolak Berkali-kali hingga Disahkan Halaman all - Kompas.com. KOMPAS.Com. https://nasional.kompas.com/read/2019/09/17/16171491/jalan-panjang-revisi-uu-kpkditolak-berkali-kali-hingga-disahkan?page=all

Ridwan, R. (2012). Peran Lembaga Pendidikan dalam Pemberantasan Tindak Pidana Korupsi di Indonesia. Jurnal Dinamika Hukum, 12(3), 547-556.

https://doi.org/10.20884/1.jdh.2012.12.3.126

Sarwono, J. (2006). Metode Penelitian Kuantitatif dan Kualitatif. Yogyakarta: Graha Ilmu.

Widjajanto, B. \& Hadjar, A. F. (2020) Reformasi di Korupsi KPK dihabisi, Sebuah Catatan Kritis". Intrans, Malang. 